Int. J. Dev. Biol. 55: 197-203 (2011)

doi: $10.1387 / \mathrm{ijdb} .103132 \mathrm{lb}$

\title{
Multi-probe in situ hybridization to whole mount Arabidopsis seedlings
}

\author{
LEONARDO BRUNO ${ }^{1}$, ANTONELLA MUTO ${ }^{1}$, NATASHA D. SPADAFORA ${ }^{1}$, DOMENICO IARIA ${ }^{1}$, \\ ADRIANA CHIAPPETTA ${ }^{1}$, MIEKE VAN LIJSEBETTENS ${ }^{2}$ and MARIA B. BITONTI*,1 \\ ${ }^{1}$ University of Calabria, Department of Ecology, Laboratory of Citofisiologia Vegetale, Arcavacata di Rende, \\ Cosenza, Italy and ${ }^{2}$ Department of Plant Systems Biology, Flanders Institute for Biotechnology and Depart- \\ ment of Molecular Genetics, Ghent University, Gent, Belgium
}

\begin{abstract}
In situ RNA-RNA hybridization (ISH) is a molecular method for localization of gene transcripts at the cellular level and is widely used to provide spatial and temporal information regarding gene expression. However, standard protocols are complex and laborious to implement, restricting analysis to one or a few genes at any one time, each one observed on separate ISH preparations. Multi-probe whole-mount in situ hybridization is a powerful technique to compare the expression patterns of two or more genes simultaneously in the same tissue or organ. We describe for the first time in plants, the detection of three different mRNAs in a single fixed whole mount Arabidopsis seedling. A combination of bright fluorescent secondary antibodies was used for the detection of riboprobes differentially labeled by digoxigenin, biotin and fluorescein. The 3-D detection of each of the multiple fluorescent hybridization signals or in combination was obtained through confocal laser-scanning microscopy. The reliability of the method was tested in the root, using the PINFORMED (PIN) genes with non-overlapping temporal and spatial expression patterns. In the shoot, a class-I KNOTTED -like homeobox gene from Arabidopsis (KNAT1) with expression restricted to the shoot apical meristem was used in combination with ELONGATOR3 (ELO3) gene. In addition, the expression patterns of ELONGATOR complex gene (ELO2, ELO3) and HISTONE MONOUBIQUITINATION1 (HUB1) genes were analyzed in both shoot and root and a partial overlapping was observed. The whole procedure takes only 6 days.
\end{abstract}

KEY WORDS: whole mount, in situ hybridization, confocal microscopy, Arabidopsis thaliana

\section{Introduction}

In multicellular organisms, the detection of the temporal and spatial expression of genes provides information on the putative sites of activity of their encoded proteins and provides novel insight into gene function in the processes of growth and development. In addition, marker gene expression is very helpful for tissue typing in mutants.

In situ RNA-RNA hybridization (ISH) is a powerful technique that enables the localization of gene transcripts at the cellular level. Riboprobes are synthesized, labeled and hybridized to mRNA derived from complementary genes, and visualized with different approaches depending on probe labeling. The ISH technique is complementary to Northern blotting and RT-PCR (reverse transcriptase-polymerase chain reaction) in which the
RNA extraction procedure invariably results in the loss of spatial information. ISH also complements DNA microarrays, a genomewide expression profiling technique, that is generally used at seedling or organ level (Chuaqui et al. 2004; Wellmer et al. 2004). Microarray resolution at the cellular level is also possible if combined with sorting of fluorescent cells derived from transgenic reporter lines. However, it requires advanced equipment and is expensive (Birnbaum et al. 2005). Spatial gene expression is also investigated through the analysis of promoter-reporter gene fusion expression. However, a limitation to this technique is that it

\footnotetext{
Abbreviations used in this paper: ELO, ELONGATOR gene; HUB, HISTONE MONOUBIQUITINATION gene; ISH, in situ hybridization; PIN, PINFORMED gene.
}

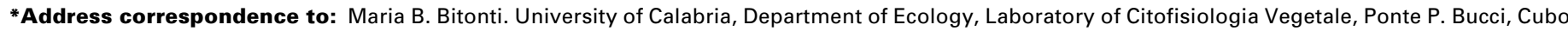
6B, 87036, Arcavacata di Rende, Cosenza, Italy. Tel: +39-09-8449-2965. Fax: +39-09-8449-2986. e-mail: b.bitonti@unical.it - web: http://ecologia.unical.it/
} 
enables the measurement of gene promoter activity, which does not necessarily correspond to the in vivo expression of the investigated gene (Taylor 1997). Indeed, regulatory elements that are usually located in the promoter and are responsible for cellspecificity or inducibility, sometimes are located in introns or coding parts of the gene. Other limitations are: i) the long half-life of their products which prevent monitoring of rapid changes in the transcription; ii) the diffusion of reporter gene products to neighboring cells resulting in artifacts (Drews et al.1992); iii) the necessity to develop transgenic lines, which is time-consuming, expensive and requires specific expertise.

On this basis, ISH is an essential technique to investigate gene expression at a cellular level. Methods for ISH, first developed in the 1980s, used radioactively labeled antisense RNA probes to detect expression of genes on histological sections prepared from wax embedded tissues and processed according to autoradiographic techniques (Harrison et al.1974). Improvements that led to safer and more accurate assays involved: i) the introduction of hapten-labeled probes that allowed the use of immunohistochemical procedures for probe detection; ii) the use of fluorophorelabeled antibodies for the detection of nucleic acids and iii) the direct (i.e. without antibodies) hybridization of fluorescently labeled nucleic acids which resolved the problems related to antibody detection through enzymatic assay per se (Bauman et al. 1980). The ISH methodologies associated with it have undergone continuous refinement (Levsky and Singer 2003). ISH performed on sections has been widely used in many model organisms, but it is time-consuming and requires much expertise.

Since the 1990s, whole mount in situ technology has eliminated the need for embedding procedures and has made the analysis of gene expression patterns rapid (Hejátko et al. 2006; Piette et al. 2008; Traas 2008; Vize et al. 2009). Originally, the whole mount in situ technology was introduced and optimized for transcript localization in animals (Kosman et al. 2004). In plants, the challenge was to overcome problems imposed by the cell wall, which can limit efficient penetration of the probe and hence hamper the hybridization outcome. Recently, whole mount in situ hybridization methods were optimized and work effectively in plants, using only one digoxigenin-labeled probe for a single whole mount (Hejátko et al. 2006; Traas 2008). However, there is a need for the simultaneous visualization of transcripts of several genes to discern whether they act in the same or different domains or tissue during plant development.

In 2004, a multiplex in situ hybridization method was implemented to detect simultaneously, a large number of different fluorescently labeled antisense RNA probes in a single wholemount Drosophila embryo (Kosman et al. 2004). In particular, this technique enabled, at high resolution, complete visualization and temporal expression of two to seven genes during embryo development in normal conditions and upon experimental treatment and genetic manipulation (Kosman et al. 2004). Recently, it was successfully adapted to mouse and Xenopus embryos (Piette et al. 2008; Vize et al. 2009). Hitherto, this has not been achieved in plant whole mounts.

Our aim was to apply multi-probe mRNA in situ hybridization, for the first time, to Arabidopsis seedlings. In particular, we used different labeled probes, detected through fluorescent antibodies, to investigate simultaneously the spatial expression of three different genes in 5-8 day old whole mount seedlings. Whole mount multi-probe ISH was combined with confocal laser-scanning microscopy, in order to obtain maximal 3D information on gene expression in whole tissues such as the primary root, hypocotyls and shoot apex. Merging of the fluorescent signals allowed us to determine whether genes were expressed in the same or in different cells, tissues or domains. Here we present a detailed protocol, recommended controls and troubleshooting advice. The method is verified in the root using PIN genes with complementary expression, and in the shoot using KNAT1 that exhibits spatial expression restricted to the shoot apical meristem (SAM). Novel expression information is presented for the ELO and HUB1 genes.

\section{Experimental Protocols}

\section{Plant material fixation and dehydration}

Seeds of Arabidopsis thaliana (L.) Heynh. ecotype Landsberg erecta (Ler) were surface sterilized by incubation in $100 \%$ ethanol for 2 min and $1.75 \%$ hypochlorite solution ( $\mathrm{NaClO}$ ) for $12 \mathrm{~min}$. After thorough washing with sterile distilled water ( $3 \times 5 \mathrm{~min})$, the seeds were sown on Petri dishes containing germination medium (GS), $1 \%$ sucrose (Valvekens et al. 1988) and $0.7 \%$ plant cell culture agar (Sigma-Aldrich). The plated seeds were left at $4^{\circ} \mathrm{C}$ for $48 \mathrm{~h}$ to ensure uniform germination, and then moved to a growth chamber at $21^{\circ} \mathrm{C}$, under $16 \mathrm{~h}\left(150 \mu \mathrm{mol} \mathrm{m} \mathrm{m}^{-2} \mathrm{~s}^{-1}\right)$ light and $8 \mathrm{~h}$ dark and $60 \%$ relative humidity. Five-to eight day-old seedlings were fixed in 15 $\mathrm{ml}$ Falcon tubes containing the fixative solution consisting of $4 \%$ (w/ v) paraformaldehyde, in 1X PBS (10X PBS: $1.3 \mathrm{M} \mathrm{NaCl}, 70 \mathrm{mM}$ $\mathrm{Na}_{2} \mathrm{HPO}_{4}{ }^{*} 2 \mathrm{H}_{2} \mathrm{O}$ and $30 \mathrm{mM} \mathrm{KH}_{2} \mathrm{PO}_{4}, \mathrm{pH}$ to 7.4 with $1 \mathrm{M} \mathrm{KCl}$ ), under vacuum until the samples were drawn to the bottom of the tube ( $20 \mathrm{~min}$ ). Samples were then transferred to plastic tubes or glass vials containing fresh fixative. Each vial was capped and taped on its side to an orbital platform shaker, and shook gently for $1 \mathrm{~h}$ at $60-80$ r.p.m at $4^{\circ} \mathrm{C}$. The fixative was then drained out, and in order to remove chlorophyll, samples were washed in methanol 2 $X 5 \mathrm{~min}$ and $3 \times 5 \mathrm{~min}$ in $100 \%$ ethanol while gently shaking, at $4^{\circ} \mathrm{C}$ Material was stored in $100 \%$ ethanol overnight at $-20^{\circ} \mathrm{C}$.

\section{Synthesizing labeled RNA probe}

Short and gene-specific fragments (GSTs) of ELO2(At5g13680), ELO3 (At5g50320), HUB1 (At2g44950), PIN1 (At1g73590) PIN4 (At2g01420); were cloned in the pGEM-TEasy vector (Promega). The following primer sequences

ELO2 FW 5'- GAAAGCGAGAGCTGAAGTCG-3' and

BW 5'- AGGCATCTGAATCTCGTGCT-3';

ELO3 FW 5'-TGAAGATACACGCCAGGACA-3' and

BW 5'-CACCAGAAATCACACCGATT-3';

HUB1 FW 5'- CATGCTCAGCAAGTTTTGGA-3' and

BW 5'- TCCCAAAATGGTTCCTCAAA-3';

PIN1 FW 5'- TCGAATCTAACCAACGCTGA-3' and

BW 5'- TCTTCCGTTTCCGTCTTGTC-3';

PIN4 FW 5'-CGAATCTTACCGGAGCTGAG and

BW 5'- GAAGCTCCTTAGCGTCATGG-3'; were used in a PCR reaction to amplify a GST. Plasmids containing DNA templates were linearized by Spel and $\mathrm{Ncol}$ endonucleases.

Labeled RNA probes were synthesized using in vitro transcription in the presence of Digoxigenin-11-UTP, Biotin-16-UTP or Fluoroscein-12-UTP by RNA polymerase T7 or SP6 (DIG, Biotin, FITC RNA labeling Mix, Roche). 
KNAT1 probe (At4g08150): PCR-based generation of template for RNA probe synthesis using KNAT1 all FW 5'CAACAGCACCACTCCTCAAA-3' and KNAT1 all BW 5'TTGTAATGCAACTCCCACCA-3'; T7 and SP6 RNA polymerase promoter should be included in the appropriate primer. Labeled RNA probes were synthesized using in vitro transcription and processed according to Hejátko (2006) and Traas (2008).

\section{Sample treatment and hybridization}

Fixed whole mount seedlings were permeabilized in a 1:1 mixture of ethanol and xylene for $30 \mathrm{~min}$, washed twice in ethanol for $5 \mathrm{~min}$ and progressively rehydrated in $75 \%$ ethanol $(\mathrm{v} / \mathrm{v}$ in water), $50 \%$ and $25 \%$ ethanol (v/v in 1 X PBS) for 10 min each. Samples were refixed in fixative solution, for $20 \mathrm{~min}$ at room temperature (RT), washed twice in PBT (1X PBS plus $0.1 \%(\mathrm{v} / \mathrm{v})$ Tween-20) for $10 \mathrm{~min}$ and then incubated with $125 \mu \mathrm{g} \mathrm{ml}^{-1}$ proteinase K (Roche) for $15 \mathrm{~min}$. Digestion was stopped by incubating the samples in $1 \mathrm{X}$ PBS plus $0.2 \%$ glycine for 5 min and then washing them twice in PBT for $10 \mathrm{~min}$. Samples were refixed in fixative solution for $20 \mathrm{~min}$ at RT, washed twice in PBT for $10 \mathrm{~min}$ and once in the hybridization solution $50 \%(\mathrm{v} / \mathrm{v})$ formamide in $5 \mathrm{X}$ SSC $(20 \mathrm{X}$ SSC: $3 \mathrm{M} \mathrm{NaCl}, 300 \mathrm{mM}$ sodium citrate, $\mathrm{pH} 7.0$ with $1 \mathrm{M} \mathrm{HCl}), 0.1 \%$ (v/v) Tween-20 and $0.1 \mathrm{mg} \mathrm{ml}^{-1}$ of heparin (Sigma) for 10min, and then preincubated in the same solution for $1 \mathrm{~h}$ at $50^{\circ} \mathrm{C}$.

The hybridization step was performed overnight at $50^{\circ} \mathrm{C}$ by incubating samples in supplemented hybridization solution (modified by adding $10 \mathrm{Mg} \mathrm{ml}^{-1}$ of Salmon sperm DNA to the hybridization solution) containing a cocktail of denatured $\left(80^{\circ} \mathrm{C}\right.$ for $\left.2 \mathrm{~min}\right)$ labeled RNA probes (20-100 ng per $\mathrm{ml}$ of the hybridization solution).

The optimal hybridization temperature was $50^{\circ} \mathrm{C}$, which ensured sufficient hybridization specificity. However, with less abundant transcript or less specific probes, $45^{\circ} \mathrm{C}$ or $55^{\circ} \mathrm{C}$, respectively gave optimal results.

\section{Post-hybridization and fluorescent detection}

Samples were washed: three times (10 min, $60 \mathrm{~min}$ and $20 \mathrm{~min}$ ) in a solution of $50 \%(\mathrm{v} / \mathrm{v})$ formamide, 2X SSC and $0.1 \%(\mathrm{v} / \mathrm{v})$

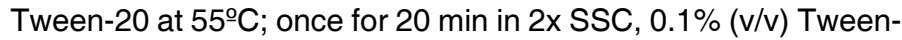

20 at $55^{\circ} \mathrm{C}$; twice for $20 \mathrm{~min}$ in $0.2 x$ SSC, $0.1 \%(\mathrm{v} / \mathrm{v})$ Tween-20 at $55^{\circ} \mathrm{C}$; three times for $10 \mathrm{~min}$ in PBT at RT; once for $30 \mathrm{~min}$ in PBT plus $1 \%$ BSA (Roche). Thereafter samples were incubated with a mixture of the selected primary antibodies (Sheep anti-digoxigenin, Roche; Mouse anti-biotin, Roche; Rabbit anti-fluorescein, Molecular Probes) diluted (1:100) in (PBT+BSA), for $2 \mathrm{~h}$ at RT under gentle shaking. Subsequently, samples were washed three times for 10 min in PBT, once for 30 min in PBT plus BSA and then incubated with a mixture of the secondary antibodies (Alexa Fluor dyes 555 Donkey Anti-Sheep, INVITROGEN; Alexa Fluor dyes 488 Donkey Anti-Mouse, INVITROGEN; Alexa Fluor dyes 647 Donkey Anti-Rabbit, INVITROGEN) diluted (1:100) in PBT plus BSA overnight at RT in the dark. After incubation samples were washed twice for 15 min in PBT under gentle shaking in the dark. In all phases of the multi-probe methodology, care was taken to ensure a complete immersion of samples in the applied solutions (use $0.5 \mathrm{ml}$ solution in a $2 \mathrm{ml}$ eppendorf tube).

Samples were mounted with antifade reagent (Fluka) on a microscope slide for viewing. Specific antifade-based mounting medium permits storage of the specimen at $-20^{\circ} \mathrm{C}$ for several months with only slight diminution of signal.

\section{Confocal visualization}

Samples were imaged using a Leica TCS SP2 (Spectral Confocal and Multiphoton System) confocal scanning laser microscope. Simultaneous detection of Alexa Fluor dyes (AF) 488, AF555 and AF647 was performed by combining the settings indicated in the sequential scanning facility of the microscope, as instructed by the manufacturer. The dye conjugates were excited at $488 \mathrm{~nm}, 555 \mathrm{~nm}$ and $647 \mathrm{~nm}$, respectively by an Ar/He/Ne laser. The fluorescence emission for $488 \mathrm{~nm}$ was collected at $517 \mathrm{~nm}$, for $555 \mathrm{~nm}$ at $569 \mathrm{~nm}$ and for $647 \mathrm{~nm}$ at $671 \mathrm{~nm}$ using a Leica 10x0.3 NA HC PL fluotar lens. Under these conditions autoflorescence was not detected. Serial optical sections of the root were collected with a mechanical focus increment of $3 \pm 0.2$ $\mu \mathrm{m}$ to a $75 \mu \mathrm{m}$ depth. Image processing and $2 \mathrm{D}$ reconstruction of serial sections was performed with Leica LCS software (Leica Microsystems, Germany). For the shoot apical meristem, single

TABLE 1

TROUBLESHOOTING

\begin{tabular}{|c|c|c|}
\hline Problem & Possible cause & Solution \\
\hline \multirow[t]{2}{*}{ Loss of morphology and tissue breaking } & Fixation problem & Respect timing of fixation and always prepare fresh fixative \\
\hline & Agitation too strong & Decrease the speed of agitation \\
\hline \multirow[t]{6}{*}{ Low or no hybridization signal } & Probe degradation & $\begin{array}{l}\text { Ensure that solution are RNAse free } \\
\text { Ensure that solution are at proper } \mathrm{pH} \\
\text { Confirm that hybridization/washing conditions are appropriate with single fluorescence in situ hybridization }\end{array}$ \\
\hline & Poor RNA synthesis & Substitute the SP6 promoter with a T3 or T7 promoter \\
\hline & RNase contamination & $\begin{array}{l}\text { Work carefully, wear gloves and } \\
\text { RNase free chemicals. }\end{array}$ \\
\hline & $\begin{array}{l}\text { Poor permeation of riboprobes or antibodies in } \\
\text { the plant tissue }\end{array}$ & $\begin{array}{l}\text { Use appropriate positive controls (riboprobes for constitutive genes or for a gene whose expression } \\
\text { pattern has been studied before) }\end{array}$ \\
\hline & $\begin{array}{l}\text { Different riboprobes might require different } \\
\text { hybridization condition }\end{array}$ & Use riboprobes of similar length and GC content \\
\hline & Tissues exposed to too much light & Protect the solution from the light \\
\hline \multirow[t]{2}{*}{ High background } & Hybridization conditions not optimized & $\begin{array}{l}\text { Hybridize sense-strand to the same sample as a control, which should yield very low to no signal } \\
\text { Increase hybridization temperature } \\
\text { Increase pos-thybridization wash temperature } \\
\text { Decrease SSC concentration in washing steps }\end{array}$ \\
\hline & Gene not expressed in the tissues & $\begin{array}{l}\text { Check available expression profiling databases and/or use RT-PCR to identify the tissue(s) and } \\
\text { condition(s), when your gene is expressed }\end{array}$ \\
\hline
\end{tabular}




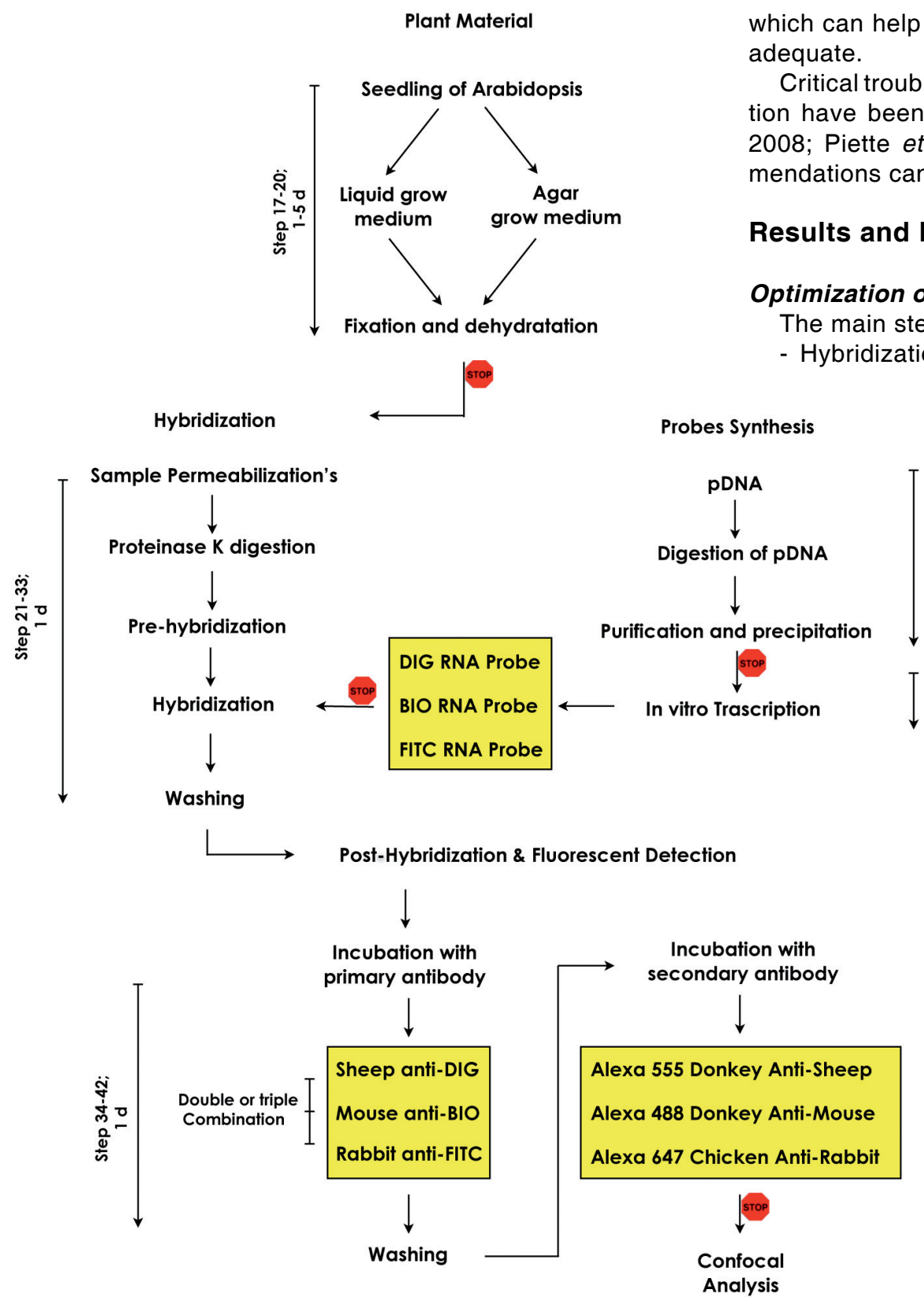

Fig. 1. Multi-color whole-mount in situ hybridization workflow. Yellow boxes highlight relevant points for the development of procedure with respect to single whole Mount ISH. Times required for each step are indicated. KEY: indicates a pause in the flow; DIG, digoxigenin; BIO, biotin; FITC, fluorescein; AF, Alexa Fluor dyes, (Molecular Probes).

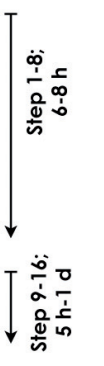
were synhesized using in vitro were synthesized using in vitro transcription in the presence of either Digoxigenin-11-UTP, or Biotin-16UTP or Fluoroscein-12-UTP to differentially label the probes. This chemical modified bases serve as haptens that can be detected using haptenspecific antibodies followed by fluorescent detection.

-In the detection phase, a cocktail of primary antibodies specifically directed against these probes was utilized. This step was followed by incubation with fluorescently labeled secondary antibodies, accurately selected for their wavelength excitation, in order to avoid overlapping of signal from different probes. Note that direct detection of fluorescein-labeled probe was excluded due to its weak sensitivity, and thus also in this case both primary and secondary antibodies were applied. Moreover, the best results were obtained by extending the incubation time with secondary antibodies to overnight and increasing the concentration of both primary and secondary antibodies (for details see experimental protocols). In the case of gene poorly expressed a peroxidase-mediated precipitation of tyramide linked fluorophores can be applied to amplify hybridization signal.

It is absolutely necessary that every multiprobe whole mount mRNA in situ hybridization experiment includes controls to determine the specificity of expression signal. For positive control, the best way is to optical section and $2 \mathrm{D}$ reconstruction of serial sections were performed with Leica LCS software (Leica Microsystems).

\section{General comments}

Before attempting to carry out the multi-probe procedure, optimal hybridization and washing conditions should be determined for each probe separately. This can be achieved with the use of single-label ISH, using the protocol detailed above (Hejátko et al. 2006), and confirmed independently by Quantitative RT-PCR (Q-PCR). These analyses allow an assessment of general patterns of expression and transcript abundance,

use simultaneously, during the multiprobe procedure, an antisense probe of a housekeeping gene with a known staining pattern. For negative controls, the best way is to test simultaneously sense probes of analyzed genes, differentially labeled as for multiprobe procedure. Another good negative control relies on the omission of secondary fluorophores-linked antibody.

An overview of the steps- from sample fixation to triple probe synthesis, simultaneous hybridization and multiplex detectionis provided in Fig. 1. Yellow boxes highlight relevant differences in the procedure with respect to single whole mount ISH. 


\section{Verification of the multi-probe ISH in the primary root}

In order to test the reliability of the method we investigated the expression pattern of two members of the PINFORMED (PIN) gene family in Arabidopsis thaliana root.

In Arabidopsis, eight PIN genes have been identified and the biological functions of five of them have been characterized (Morris et al. 2004; Paponov et al. 2005). PIN genes encode plasma membrane-associated proteins (PIN), called auxin efflux facilitators, which control polar flow of the phytohormone auxin and are characterized by cell type specific polar localization. The polar cell-to-cell flow of auxin underlies multiple developmental processes in plants (Vanneste and Friml 2009).

For our analysis we selected PIN1 and 4 genes, known to be expressed at low levels, as judged by single whole mounts, and to exhibit distinct expression patterns in root tissues (Blilou et al. 2005). Under our experimental conditions, PIN1 localized in the stele and more weakly in the cortex and in the epidermis (Fig. 2 A, E, C, G). PIN4 was instead detected in the quiescent centre and cells surrounding it and in provascular cells of stele (Fig. $2 \mathrm{~B}$, $F, C, G)$. Thus, the results reported here confirm in the same individual the previous findings obtained by Blilou (2005) and Vieten (2005).

\section{Verification of the multi-probe ISH in the shoot of apical meristem}

In order to confirm the reliability of the method in the SAM we investigated the expression pattern of KNAT1, a member of the class-I KNOTTED-like homeobox (KNOX) gene family exhibiting a well defined expression domain, in combination with ELO3 gene.

The plant class 1 KNOX genes encode homeodomain-(HD) containing transcription factors (TFs). They are differentially required for SAM establishment and function and constitute a pathway that controls meristem cell fate (Reiser et al. 2000; Hake et al. 2004). In simple-leafed species, these genes are typically expressed in the SAM, but their down-regulation is required both at the leaf initiation site of the SAM (PO), the leaf primordium and throughout leaf development (Hay and Tsiantis, 2006). In Arabidopsis class 1 KNOX genes include KNAT1, also named
BREVIPEDICELLUS (BP), KNAT2, and KNAT6 (Reiser et al. 2000).

Regarding ELO3, it is a component of a conserved histone acetyl transferase (HAT) complex, consisting of six subunits, that co localizes with the elongating RNAP II in plants and targets auxin-related genes for histone $\mathrm{H} 3$ acetylation. elo mutants were originally identified as leaf mutants but also have auxin-related phenotypes (Nelissen et al. 2005; 2010). Recently, ISH has been applied to investigate tissue or domain specific expression pattern of ELO genes in Arabidopsis plants by using single probes (Nelissen et al. 2010). Results showed that ELO genes were expressed predominantly in the meristematic tissues (shoot apical meristem, provascular strands of young seedlings, meristematic and elongation zone of the primary and lateral root tip) suggesting that Elongator complex formation is restricted to actively dividing tissues (Nelissen et al. 2010).

Using multi-probe in situ hybridization, we observed that in the aerial organ of young seedling (i.e. SAM and developing leaves) the spatial expression of KNAT1 was restricted to the SAM and absent in the developing leaves (Fig.3 B, E, C, F). Thus, the result reported here fully matches that previously obtained by Lincoln (1994). Whereas, ELO3 expression was present in the SAM, in the emerging leaf primordia and provascular strands (Fig. $3 \mathrm{~A}, \mathrm{D}$, $\mathrm{C}, \mathrm{F}$ ), thus confirming expression pattern previously obtained by Nelissen (2010). By merging the two expression patterns, in the same sample an overlapping of KNAT1 and ELO3 fluorescent signals, tightly confined to the SAM, was clearly observed (Fig. 3 C, F).

\section{ELO and HUB1 gene expression patterns partially overlap in the shoot and root}

The next set of genes were ELO2, ELO3 and HUB1, all involved in activating transcription through histone modification. In particular, HUB1 encodes the functional homolog of yeast and human histone H2B monoubiquitinating BRE1 RING E3 ligases, and has a role in plants in the regulation of the cell cycle during early organ growth (Fleury et al. 2007). However, the HUB1 spatial expression pattern has not been investigated by ISH before in plants, but RT-PCR and pHUB1-GUS analyses showed
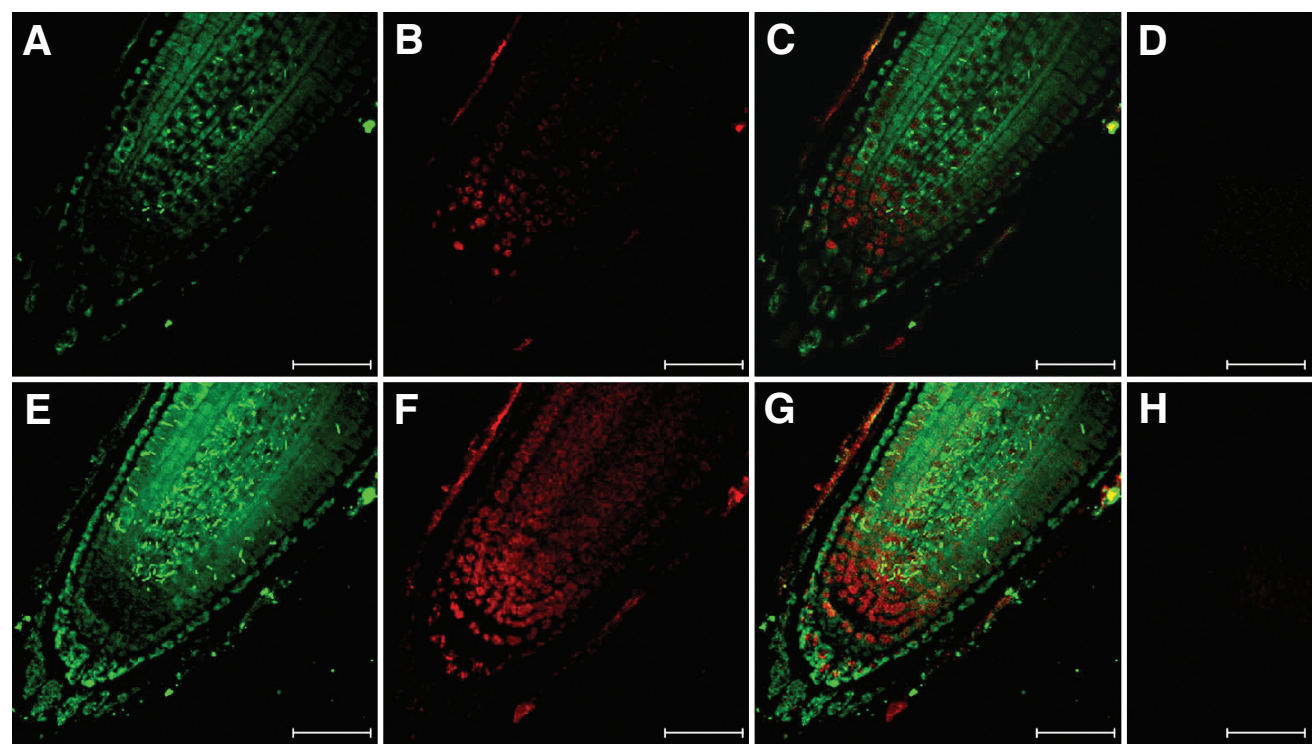

Fig. 2. Double multi-color fluorescent in situ hybridization in Arabidopsis seedling root tips (A-H). Images were acquired on a Leica SP2 confocal microscope with a $40 X$ oil immersion objective. Green: (A) PIN1 BIO riboprobe, mouse anti-BIO and AF488 donkey anti-mouse. Red: (B) PIN4 DIG riboprobe, sheep anti-DIG and AF555 donkey anti-sheep; (C) merge and (D) PIN1 sense control. 2D Maximum projection from a z-stack assembly (E-G), images were acquired on a Leica SP2 confocal microscope with a 40X oil immersion objective. Green: (E) PIN1 BIO riboprobe, mouse anti-BIO and AF488 donkey antimouse. Red: (F) PIN4 DIG riboprobe, sheep anti-DIG and AF555 donkey anti-sheep (G) merge and (H) PIN4 sense control. KEY: DIG, digoxigenin; BIO, biotin; FITC fluorescein; AF, Alexa Fluor dyes, (Molecular Probes). Set. Scale bars, $75 \mu \mathrm{m}(A-H)$. 

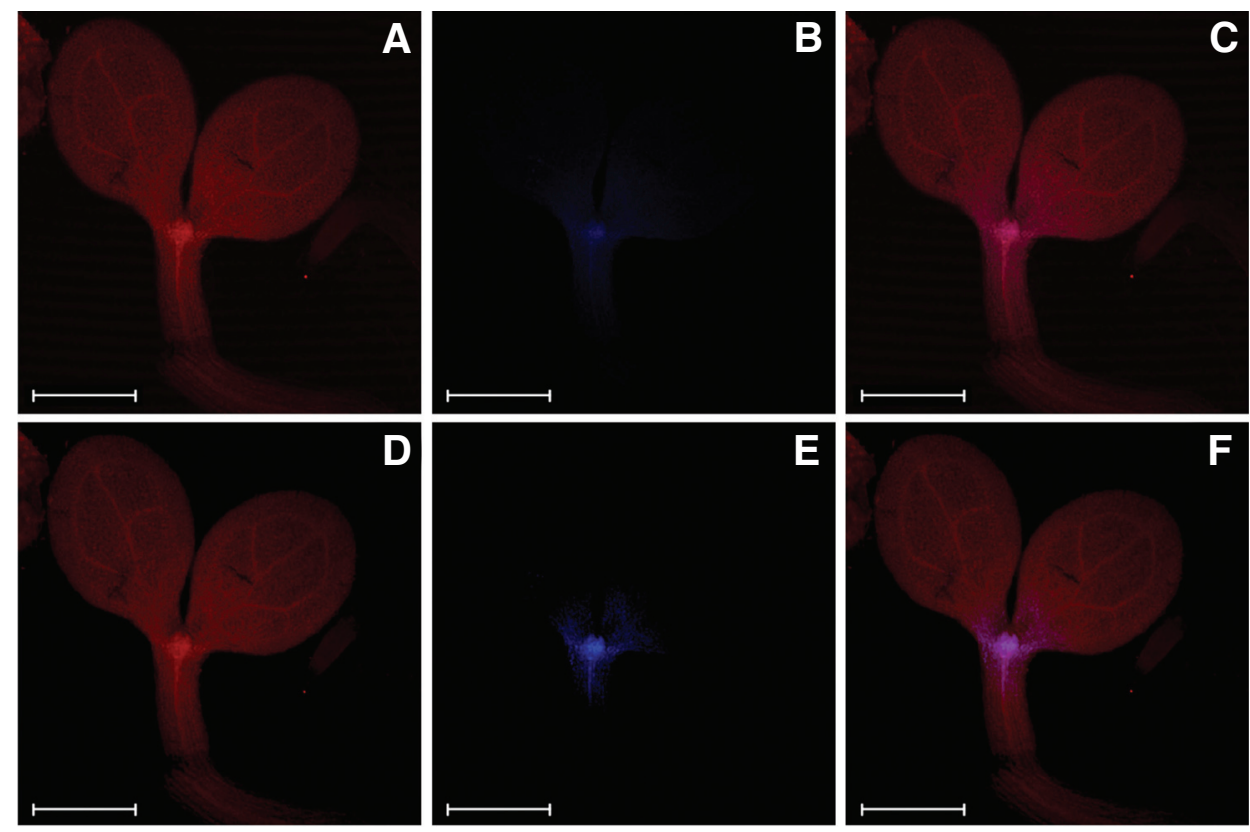

Fig. 3. Double multi-color fluorescent in situ hybridization in Arabidopsis seedling shoot apices (A-F). Images were acquired on a Leica SP2 confocal microscope with a 10X objective. Red: (A,D) ELO3 DIG riboprobe, sheep anti-DIG and AF555 donkey anti-sheep. Blue: (B,E) KNAT1 FITC riboprobe, rabbit anti-FITC and AF647 chicken anti-rabbit; (C,F) merge 2D Maximum projection from a z-stack assembly (D-F), images were acquired on a Leica SP2 confocal microscope with a $40 X$ oil immersion objective. Red: (D) ELO3 DIG riboprobe, sheep anti-DIG and AF555 donkey anti-sheep. Blue: (E) KNAT1 FITC riboprobe, rabbit anti-FITC and AF647 chicken anti-rabbit; (F) merge. KEY: DIG, digoxigenin; FITC, fluorescein; AF, Alexa Fluor dyes, (Molecular Probes). Set. Scale bars, 300 um (A-F).

respectively $H U B 1$ gene expression or promoter activity in roots, stems, leaves and flowers (Liu et al. 2007).

Using the Multi-probe whole mount, we observed a clear overlapping of ELO2 and ELO3 fluorescent signals in the SAM, emerging leaf primordia and provascular strands of young seedlings (Fig. $4 \mathrm{~A}, \mathrm{~B}, \mathrm{D}$ ), in the meristematic and elongation zone of the primary root tip while probe signals were absent in the differentiation zone (Fig. 4 E, F, H). Thus, we demonstrate in the same sample and in the entire organ, that two ELO genes have identical developmental expression patterns as previously stated by comparing gene expression in different samples (Nelissen et al. 2010).

Concerning HUB1 gene, we observed that in the aerial organ of young seedling (i.e. SAM and developing leaves) its spatial expression overlapped with that of ELO genes (Fig. 4 C, D). In the primary root, HUB1 transcripts mainly accumulated in the protodermal cell layer of the meristematic and elongation zone in contrast to ELO transcripts that were abundant in the whole meristematic dome, as well as along protoderm, cortex and, even if to a less extent, in the vascular stele of elongation zone (Fig. 4 G, H). Thus, HUB1 expression pattern overlaps fully with those of $E L O$ genes in the shoot, but it differs in the primary root suggesting a differential tissue specific role for the HUB1 and ELO genes in the Arabidopsis root.

\section{Conclusions}

We applied for the first time a functional and reproducible procedure for multi-probe whole mount mRNA in situ hybridization in Arabidopsis seedlings, based on the method described by Hejátko (2006). The success of this procedure depends on the specific labeled probes used for the hybridization, and the choice of appropriate primary antibodies from different host species, as well as spectrally separable fluorescent secondary antibodies for visualization in a multichannel confocal laser microscopy.

In conclusion the method described here provides a fast and efficient tool to simultaneously define the in situ expression pattern of several genes at high resolution in plants.

\section{Acknowledgements}

We especially thank Prof. Dennis Francis for the helpful suggestions
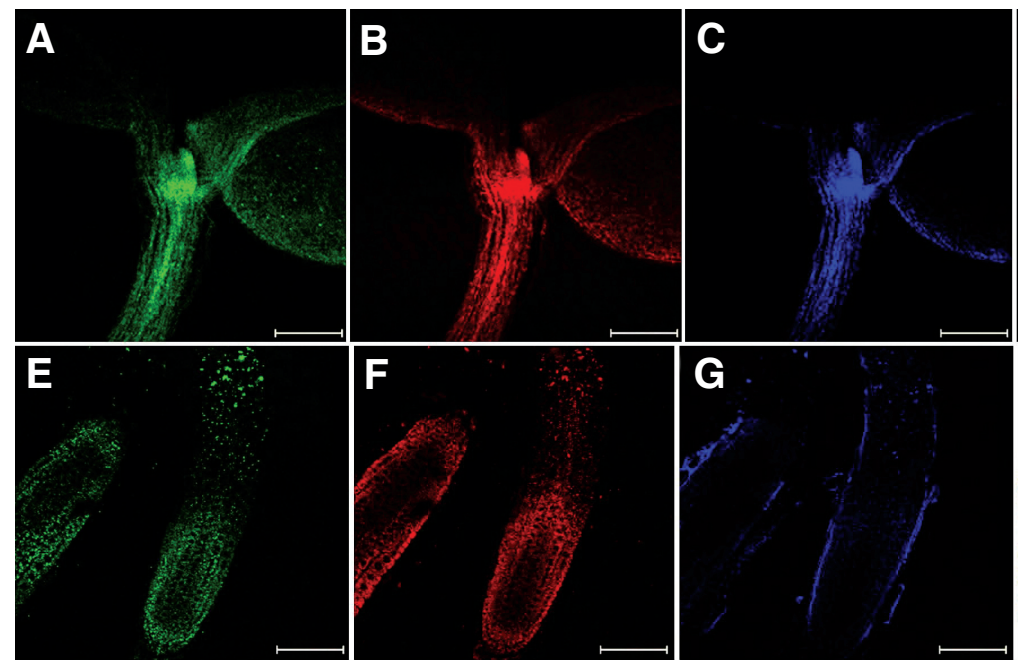

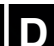

D

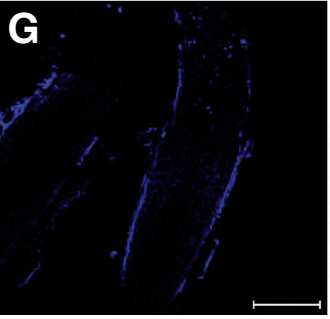

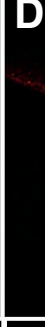

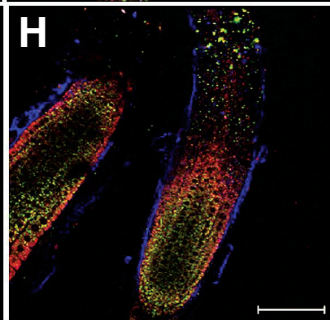

Fig. 4. Triple-label whole-mount fluorescent in situ hybridization in a seedling shoot apical meristem (AD), and in a seedling root apical meristem (E-H). Images were acquired on a Leica SP2 confocal microscope with a 20X objective for (A-D) and a 40X oil immersion objective for (E-H). Green: (A,E) ELO2 BIO riboprobe, mouse anti-BIO and AF488 donkey antimouse; Red: (B,F) ELO3 DIG riboprobe, sheep anti-DIG and AF555 donkey antisheep; Blue: (C,G) HUB FITC riboprobe, rabbit anti-FITC and AF647 chicken antirabbit; Merge (D,H). Key: DIG, digoxigenin; BIO, biotin; FITC, fluorescein; AF, Alexa Fluor dyes, (Molecular Probes). Set. Scale bars, $345 \mu \mathrm{m}$ (AD), $75 \mu \mathrm{m}$ (E-H) 
and comments on the manuscript, and for the critical reading of the manuscript. This work was supported by grants from the Italian Ministry for research and Technology (MIUR). N.D.S is a post-doc fellow supported by AQP PON 07-13 - Action 2 Laboratorio "Mission Oriented" AGRIBIOTECH.

\section{References}

BAUMAN, J.G., WIEGANT, J., BORST, P., VAN DUIJN, P. (1980). A new method for fluorescence microscopical localization of specific DNA sequences by in situ hybridization of fluorochromelabelled RNA. Exp Cell Res 128: 485-490.

BIRNBAUM, K., JUNG, J.W., WANG, J.Y., LAMBERT, G.M., HIRST, J.A., GALBRAITH, D.W. AND BENFEY, P.N. (2005). Cell type-specific expression profiling in plants via cell sorting of protoplasts from fluorescent reporter lines. Nat Methods 2: 615-619.

BLILOU, I., XU, J., WILDWATER, M., WILLEMSEN, V., PAPONOV, I., FRIML, J., HEIDSTRA, R., AIDA, M., PALME, K. AND SCHERES, B. (2005). The PIN auxin efflux facilitator network controls growth and patterning in Arabidopsis roots. Nature 433: 39-44.

CHUAQUI, R.F., BONNER, R.F., BEST, C.J., GILLESPIE, J.W., FLAIG, M.J., HEWITT, S.M., PHILLIPS, J.L., KRIZMAN, D.B., TANGREA, M.A., AHRAM, M., LINEHAN, W.M., KNEZEVIC, V. AND EMMERT-BUCK, M.R. (2004). Postanalysis follow-up and validation of microarray experiments. Nat Genetics 32: $509-514$.

DREWS, G.N., BEALS, T.P., BUI, A.Q. AND GOLDBERG, R.B. (1992). Regional and cell-specific gene expression patterns during petal development. Plant Cell 4: 1383-1404.

FLEURY, D., HIMANEN, K., CNOPS, G., NELISSEN, H., BOCCARDI, T.M., MAERE, S., BEEMSTER, G.T., NEYT, P., ANAMI, S., ROBLES, P., MICOL, J.L., INZÉ, D. AND VAN LIJSEBETTENS, M. (2007). The Arabidopsis thaliana homolog of yeast BRE1 has a function in cell cycle regulation during early leaf and root growth. Plant Cell 19: 417-432.

HAKE, S., SMITH, H.M.S, HOLTAN, H., MAGNANI, E., MELE, G. AND RAMIREZ, J. (2004). The role of KNOX genes in plant development. Annual Rev Cell Dev Biol 20: 125-151.

HARRISON, P.R., CONKIE, D., AFFARA, N. AND PAUL, J. (1974). In situ localization of globin messenger RNA formation I. during mouse fetal liver development. J Cell Biol 63: 401-413.

HAY, A. AND TSIANTIS, M. (2006). The genetic basis for differences in leaf form between Arabidopsis thaliana and its wild relative Cardamine hirsuta. Nat Gen 8: 942-947.

HEJÁTKO, J., BLILOU, I., BREWER, P.B., FRIML, J., SCHERES, B. AND BENKOVÁ, E. (2006). In situ hybridization technique for mRNA detection in whole mount Arabidopsis samples. Nat Prot 4: 1939-1946.

KOSMAN, D., MIZUTANI, C.M., LEMONS, D.,nCOX, W.G., MCGINNIS, W. AND BIER, E. (2004). Multiplex detection of RNA expression in Drosophila embryos. Science 305: 846.

LEVSKY, J.M. AND SINGER, R.H. (2003). Fluorescence in situ hybridization: past, present and future. J Cell Sci 116: 2833-2838.

LINCOLN C, LONG J, YAMAGUCHI J, SERIKAWA K AND HAKE S. (1994). A knotted1-like homeobox gene in Arabidopsis is expressed in the vegetative meristem and dramatically alters leaf morphology when overexpressed in transgenic plants. Plant Cell 6: 1859-1876.

LIU, Y., KOORNNEEF, M. AND SOPPE, W.J.J. (2007). The absence of histone H2B monoubiquitination in the Arabidopsis hub1 (rdo4) mutant reveals a role for chromatin remodeling in seed dormancy. Plant Cell 19: 433-444.

MORRIS, D.A., FRIML, J. AND ZAZIMALOVA, E. (2004). Auxin transport. In Plant Hormones: Biosynthesis, Signal Transduction. Action! (Ed. Davies P.J.,) Dordrecht: The Netherlands, Kluwer Academic Publishers pp. 437-470.

NELISSEN, H., FLEURY, D., BRUNO, L., ROBLES, P., DE VEYLDER, L., TRAAS, J., MICOL, J.L., VAN MONTAGU, M., INZÉ, D. AND VAN LIJSEBETTENS, M. (2005). The elongata mutants identify a functional Elongator complex in plants with a role in cell proliferation during organ growth. Proc Natl Acad Sci USA 102: 7754-7759.

NELISSEN, H., DE GROEVE, S., FLEURY, D., NEYT, P., BRUNO, L., BITONTI, M.B., VANDENBUSSCHE, F., VAN DER STRAETEN, D., YAMAGUCHI, T., TSUKAYA, H., WITTERS, E., DE JAEGER, G., HOUBEN, A. AND VAN LIJSEBETTENS, M. (2010). Plant Elongator regulates auxin-related genes during RNA polymerase II transcription elongation. Proc NatI Acad Sci USA 107: 1678-1683.

PAPONOV, I.A., TEALE, W.D., TREBAR, M. AND BLILOU, I. (2005). Palme K The PIN auxin efflux facilitators: evolutionary and functional perspectives. Trends Plant Sci. 4: 170-177.

PIETTE, D., HENDRICKX, M., WILLEMS, E., KEMP, C.R. AND LEYNS, L. (2008). An optimized procedure for whole-mount in situ hybridization on mouse embryos and embryoid bodies. Nat Prot 3: 1194- 1201.

PINAUD, R., MELLO, C. V., VELHO, T. A., WYNNE, R. D. AND TREMERE, L. A (2008). Detection of two $m$ RNA species at single-cell resolution by doublefluorescence in situ hybridization. Nat Prot 3: 1370-1379.

REISER, L., SANCHEZ-BARACALDO, P. AND HAKE, S. (2000). Knots in the family tree, evolutionary relationships and functions of knox homeobox genes. Plant Mol. Biol. 42: 151-166.

TAYLOR, C. (1997). Promoter fusion analysis: an insufficient measure of gene expression. Plant Cell 9: 273-275.

TRAAS, J. (2008). Whole-Mount In situ Hybridization of RNA Probes to Plant Tissues. Cold Spring Harb Protoc pdb prot 4944.

VALVEKENS, D., VAN MONTAGU, M. AND VAN LIJSEBETTENS, M. (1988). Agrobacterium tumefaciens-mediated transformation of Arabidopsis thaliana root explants by using kanamycin selection. Proc Nat Acad Sci USA 85: 55365540.

VANNESTE, S. AND FRIML, J. (2009). Auxin: A Trigger for Change in Plant Development. Cell 6: 1005-1016.

VIETEN, A., VANNESTE, S., WISNIEWSKA, J., BENKOVÁ1, E., BENJAMINS, R. BEECKMAN, T., LUSCHNIG, C. AND FRIML, J. (2005). Functional redundancy of PIN proteins is accompanied by auxin-dependent cross-regulation of PIN expression. Development 132: 4521-4531.

VIZE, P.D., MCCOY, K.E. AND ZHOU, X. (2009). Multichannel whole mount fluorescent and fluorescent/chromogenic in situ hybridization in Xenopus embryos. Nat Prot 4: 975-983.

WELLMER, F., RIECHMANN, J.L., ALVES-FERREIRA, M. AND MEYEROWITZ, E.M. (2004). Genome-wide analysis of spatial gene expression in Arabidopsis flowers. Plant Cell 16: 1314-1326. 


\section{Further Related Reading, published previously in the Int. J. Dev. Biol.}

Expression of DOF genes identifies early stages of vascular development in Arabidopsis leaves Jason Gardiner, Ira Sherr and Enrico Scarpella Int. J. Dev. Biol. (2010) 54: 1389-1396 (doi: 10.1387/ijdb.093006jg)

Lessons from a search for leaf mutants in Arabidopsis thaliana José Manuel Pérez-Pérez, Héctor Candela, Pedro Robles, Víctor Quesada, María Rosa Ponce and José Luis Micol Int. J. Dev. Biol. (2009) 53: 1623-1634

\section{Chromatin remodeling in plant development} José A. Jarillo, Manuel Piñeiro, Pilar Cubas and José M. Martínez-Zapater Int. J. Dev. Biol. (2009) 53: 1581-1596

\section{Common themes in siRNA-mediated epigenetic silencing pathways}

André Verdel, Aurélia Vavasseur, Madalen Le Gorrec and Leila Touat-Todeschini Int. J. Dev. Biol. (2009) 53: 245-257

Arabidopsis monomeric G-proteins, markers of early and late events in cell differentiation Mariette Bedhomme, Chantal Mathieu, Amada Pulido, Yves Henry and Catherine Bergounioux Int. J. Dev. Biol. (2009) 53: 177-185

5 yr ISI Impact Factor $(2009)=3.253$
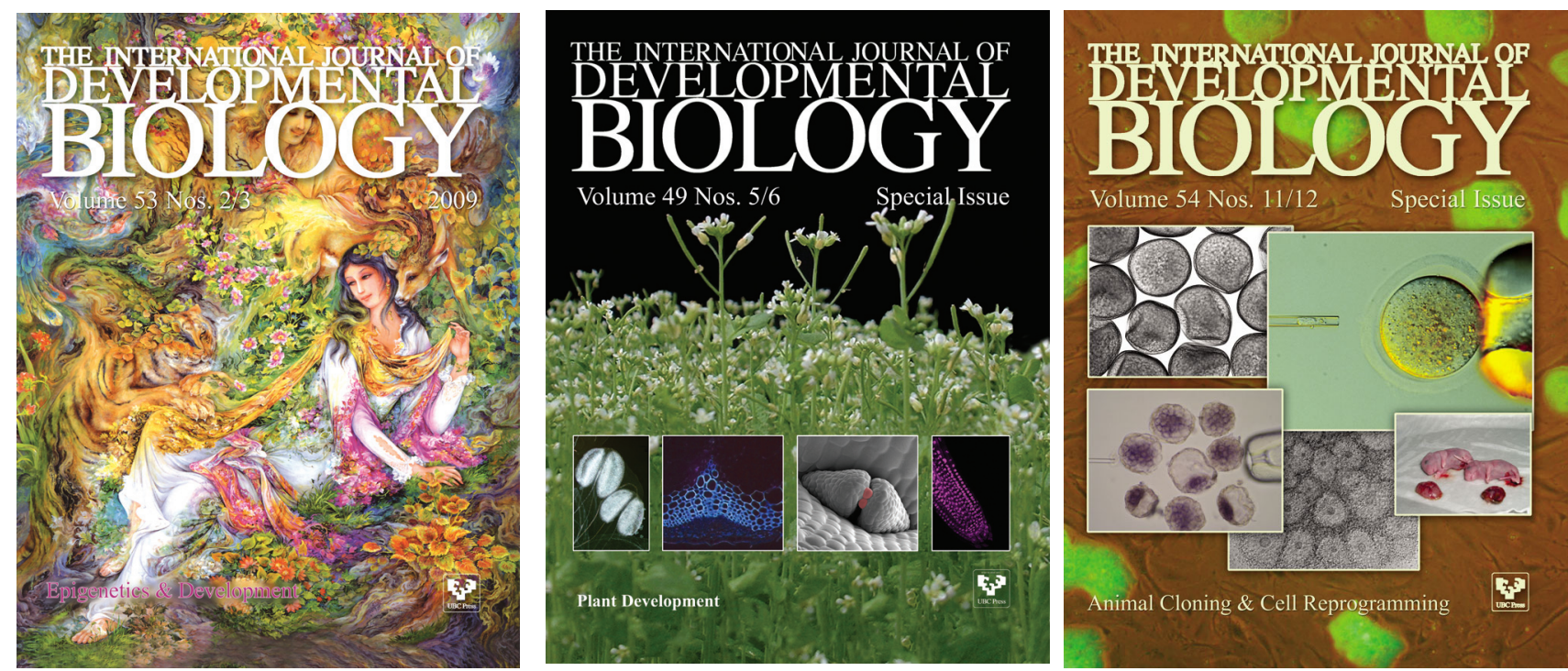